\title{
A Proposed Supplementary Teaching Materials in Teaching Grade 7 Mathematics: Its Acceptability
}

\author{
Meriam Villareal Dela Cruz \\ General Education Department, Eulogio “Amang” Rodriquez Institute of Science and Technology (EARIST), Manila, Philippines \\ Email address: \\ meriamvdc2018@gmail.com \\ To cite this article: \\ Meriam Villareal Dela Cruz. A Proposed Supplementary Teaching Materials in Teaching Grade 7 Mathematics: Its Acceptability. \\ International Journal of Secondary Education. Vol. 7, No. 1, 2019, pp. 6-10. doi: 10.11648/j.ijsedu.20190701.12
}

Received: November 14, 2018; Accepted: January 10, 2018; Published: April 1, 2019

\begin{abstract}
The researcher aimed to conduct a study which will help the learners understand more on their lessons especially during the second quarter topics. Supplementary teaching materials can help improve the performance of the students which will lead to a better performance. Based on the findings, there is a significant difference between the pretest and posttest of the students after using the proposed teaching material. It was shown that the teaching material was advantageous to the students' performance because after using the teaching material their performance became better. The two groups of respondents show that their evaluation about the proposed supplementary teaching material are both the same which is to accept the said teaching material. After using the proposed teaching material the performance of the students improved.
\end{abstract}

Keywords: Acceptability, Assessment, Mathematics Experts, Supplementary Learning Materials, Worktext

\section{Introduction}

Mathematics plays an important role and receives special attention in the $\mathrm{K}$ to 12 Curriculum. Therefore, in order to keep with the pacing, teachers should be equipped with the armory of teaching tools not only depending on chalk talk but also with the different ways and techniques on how to gain the attention of the students to impart knowledge. Students nowadays are not focused. They don't care on what the teachers are teaching especially when they found it unattractive and hard to understand. Learners always prefer on what they think is easy and don't need much effort to understand it.

Balando (2011) emphasized that the focus of her experimental study was to determine the effectiveness of an online interactive multimedia learning tool versus text only, text and images, and multimedia learning explanations on math achievement, math self-efficacy, and student satisfaction. Compared to students in the control group, students in the interactive multimedia group were more satisfied with the method of learning, reported the technique to be enjoyable and interesting, and provided sufficient feedback. [1].

Kirk (2011) asserted computer instructional approach is supported by the early work of Johnson (1974). One of the eleven recommendations for effectively serving remedial students is to accommodate individual differences and permit students to learn at their own pace. Developmental students typically do not have the reading and listening skills to succeed in traditional instruction. They learn best by being active learning, and by seeing. Four criteria formed the basis of the construct of teacher capacity: knowledge of mathematics, interpretation of the intentions of official curriculum documents, understanding of students' thinking, and design of teaching. While these key elements to what other researchers refer to as mathematical knowledge for teaching, several differences are made clear. [2].

According to Magcalen (2011), from all the research findings on the use of computers in teaching and learning Mathematics, it appears that it has a great potential to improve mathematics education. [3].

The study of Acuna (2012) entitled, "Interactive Multimedia Instructional Materials: A guidance Intervention Model in Teaching Mathematics for Grade II" concluded that the developed Interactive multimedia device helped a lot to increase the performance level of the pupils. The materials were also highly accepted by the school administrator and teacher respondents. The t-test result showed that the findings of the study were significantly difference from each other. [4].

In a country like the Philippines where access to technology is gradually taking off, the use of technology has been seen possible way of enhancing learning. It was assumed that all students had 
access to the internet but still, there were handful of students who had difficulties in regularly going online. Nevertheless, just because of more classroom time devoted to students' interaction, the value of migrating many classroom components online is seen as advantageous [5]. When the students understand the topic being taught, they can see similarities and differences. They are able to compare and contrast as well as understand and analyze. Learning becomes more meaningful when lessons are applied to real life situation. [6].

Either in the face - to - face or virtual classroom, an instructor-led environment where the learners must absorb information, mental load is high or to engage in secondary activity as extensive note taking will overload memory and depress learning when the learner has the control over the rate of instruction. It is such a persuasiveactivity during learning. For example, when reading a text or reviewing instruction, taking notes helps build new knowledge structures in memory. In contrast, taking detailed notes of a lesson in virtual classroom will more often than not cause distraction. It is therefore not advisable to have learning as well as taking notes while in teaching-learning process so as not to barge the working memory of the learner [7]. The study presented faceto-face learnings merged to develop supplementary learning materials using computer instructional approach as a tool. The tool was developed to address the issues of learning using the computer discussed in this study. Its emphasis is to have continuity of learning done in traditional classroom to stimulate social interaction between student-to-student and sustain feedback mechanism on the resources of the faculty-tostudent and sustain feedback mechanism to achieve the complete learning process. The tool was implemented based on the resources of the school, community and students. [8].

The country needs Mathematics to take part in national problems, to help show the way toward the path of peace and prosperity by eliminating the ills of society that plague the nation today. The importance of mathematics in the world of education is as important as the needs for growth in the economy. [9].

The researcher working for a teaching material which will help the teachers teach and make the lesson more understandable and catch the attention and interest of the learners, and it is the worktext. Its pages filled with activities which follows lessons with some kinds. Worktext attracts learner's interest to learn and do more activities related to the topic or lessons presented.

The researcher ensures that the worktext will be helpful not only for the teachers or the students but to both. The researcher also made the worktext attractive, readable enough, simply and easy to understand so that students will be interested and won't get bored while using the worktext.

The study hypothesized that there is no significant difference on the assessment of the experts and teachers on the acceptability of the Supplementary Teaching Materials. There is no significant difference in the performance of the students in pretest and posttest.

The importance of the supplementary teaching material as an instrument for development of the Mathematics subject for the learners in grade 7 is predictable. The researcher believes that the enhancement materials, the use of worktext as a teaching material in teaching grade 7 Mathematics is significant so that a better way of transmitting knowledge and 10 learning in Grade 7 Mathematics will be unearthed. Likewise, the result of the study is immense value as worthwhile contributions to the following:

a. Students- They will be more interested in understanding the lessons through pictures, figures or concepts presented in the worktext.

b. Mathematics Teachers- This will help in the delivery of their lessons in simplified manner which will help the students to understand easily and attract the interest of the learners to learn more about the topic presented.

c. School administrator- The study may give them a lot of insights in the utilization of different teaching materials, especially in teaching grade 7 Mathematics as it expected to serve as tools for improving the quality and relevance of education.

d. Researchers- The study will serve as an inspiration and guide for those researchers who are seeking more heights in improving teaching material specifically in the adaptation of supplementary teaching materials in teaching grade 7 Mathematics as an effective tool for learning.

\section{Materials and Methods}

The study applied the descriptive method in conducting this study to determine the acceptability of the proposed supplementary teaching material in teaching grade 7 Mathematics. The purposive sampling was used in the study. Purposive because only high school Mathematics teachers teaching Mathematics at Carlo P. Garcia High School were included and the grade 7 students who are taking Mathematics 7 were involved in the study. On the other hand, descriptive method of research is an attempt of finding generalization that attributes to present conditions. This method was used in determining the validity of the presentations as instructional material. [10].

For the population and sampling, it used purposive sampling was used in the study. Purposive because only high school Mathematics teachers teaching Mathematics at Carlo P. Garcia High School were included and the grade 7 students who are taking Mathematics 7 were involved in the study.

Table 1. Distribution of Respondents as to Experts, Math Teachers, and Students.

\begin{tabular}{llll}
\hline & Population & Sample & Percentage \\
\hline Experts & 15 & 15 & 29 \\
Math Teachers & 7 & 7 & 13 \\
Grade 7 Students of CPGHS & 30 & 30 & 58 \\
Total & 52 & 52 & 100 \\
\hline
\end{tabular}

The data in table 1 shows the distribution of respondents as to experts, math teachers, and students, looking at the data $29 \%$ 
are experts, $13 \%$ are math experts and $58 \%$ are students with a total of 52 respondents who 29 assessed and validated the proposed supplementary teaching material in teaching grade 7 mathematics.

Table 2. Profile of Respondents as to Educational Attainment.

\begin{tabular}{|c|c|c|c|c|c|c|}
\hline \multirow{2}{*}{ Educational Attainment } & \multicolumn{2}{|c|}{ Experts } & \multicolumn{2}{|c|}{ Math Teachers } & \multicolumn{2}{|c|}{ Total } \\
\hline & $\mathbf{F}$ & $\%$ & $\mathbf{F}$ & $\%$ & $\mathbf{F}$ & $\%$ \\
\hline Master's Degree & 4 & 27 & 1 & 14 & 5 & 23 \\
\hline w/Master's Unit & 8 & 53 & 6 & 86 & 14 & 64 \\
\hline Bachelor's Degree & 3 & 20 & 0 & 0 & 3 & 13 \\
\hline Total & 15 & 100 & 7 & 100 & 22 & 100 \\
\hline
\end{tabular}

Table 2 shows the profile of respondents as to educational attainment, it can be gleaned from this table that 4 or 27 percent of experts are with master's degree, 8 or 53 percent are with master's unit, and 3 or 20 percent are with bachelor's degree. Nobody earned doctorate degree. On the other hand, most of the Math teachers, 6 or 86 percent are with master's unit, and 1 or 14 percent is with master's degree.

Table 3. Profile of Respondents as to Length of Service.

\begin{tabular}{|c|c|c|c|c|c|c|}
\hline \multirow{2}{*}{ Length of Service } & \multicolumn{2}{|c|}{ Experts } & \multicolumn{2}{|c|}{ Math Teachers } & \multicolumn{2}{|c|}{ Total } \\
\hline & $\mathbf{F}$ & $\%$ & $\mathbf{F}$ & $\%$ & $\mathbf{F}$ & $\%$ \\
\hline 16 yrs. and above & 10 & 67 & 3 & 42 & 13 & 59 \\
\hline $11-15$ yrs. & 0 & 0 & 2 & 29 & 2 & 9 \\
\hline $6-10 \mathrm{yrs}$. & 0 & 0 & 0 & 0 & 0 & 0 \\
\hline Below 5 yrs. & 5 & 33 & 2 & 29 & 7 & 32 \\
\hline Total & 15 & 100 & 7 & 100 & 22 & 100 \\
\hline
\end{tabular}

Table 3 shows the profile of respondents as to length of service, It can be gleaned from this table that 10 or 67 percent of experts are 16 years and above in service and 5 or 33 percent are 5 years and below in service, on the other hand, 3 or 42 percent of math teachers are 16 years and above in service, 2 or 29 percent are 11-15 years in service and 2 or 29 percent are 5 years and below in the service in teaching Mathematics.

Table 4. Profile of Respondents as to Age.

\begin{tabular}{lllllll}
\hline \multirow{2}{*}{ Age } & Experts & \multicolumn{3}{c}{ Math Teachers } & Total & \\
\cline { 2 - 7 } & f & $\mathbf{\%}$ & f & $\mathbf{\%}$ & f & \% \\
\hline 46 yrs. and above & 11 & 73 & 5 & 71 & 16 & 73 \\
36-45 yrs. & 1 & 7 & 0 & 0 & 1 & 4.5 \\
26-35 yrs. & 2 & 13 & 2 & 19 & 4 & 18 \\
Below 25 yrs. & 1 & 7 & 0 & 0 & 1 & 4.5 \\
Total & 15 & 100 & 7 & 100 & 22 & 100 \\
\hline
\end{tabular}

Table 4 shows the data on the profile of respondents as to their age, it can be gleaned from this table that 11 or 73 percent of experts are 45 years old and above, 1 or 7 percent is 36- 45 years old, 2 or 13 percent are 26-35 years old and 1 or 7 percent is 25 years old and below. On the other hand, 5 or 71 percent of Math teachers are 46 years old and above, 2 or 29 percent are 26-35 years old.

Table 5. Profile of Respondents as to Civil Status.

\begin{tabular}{lllllll}
\hline \multirow{2}{*}{ Age } & Experts & & Math Teachers & \multicolumn{2}{c}{ Total } \\
\cline { 2 - 7 } & f & $\mathbf{\%}$ & f & $\mathbf{\%}$ & f & \% \\
\hline Single & 3 & 20 & 3 & 43 & 6 & 27 \\
Married & 11 & 73 & 4 & 57 & 15 & 68 \\
Widow & 1 & 7 & 0 & 0 & 1 & 45 \\
Total & 15 & 100 & 7 & 100 & 22 & 100 \\
\hline
\end{tabular}

Table 5 shows the profile of respondents as to civil status, it can be gleaned from this table that 3 or 20 percent of experts are single, 11 or 73 percent are married, 1 or 7 percent is widow and no one is separated. On the other hand, 3 or 43 percent of math teachers are single, 4 or 57 are married. No one is separated.

Table 6. Profile of Respondents as to Civil Gender.

\begin{tabular}{|c|c|c|c|c|c|c|}
\hline \multirow{2}{*}{ Gender } & \multicolumn{2}{|c|}{ Experts } & \multicolumn{2}{|c|}{ Math Teachers } & \multicolumn{2}{|c|}{ Total } \\
\hline & f & $\%$ & f & $\%$ & f & $\%$ \\
\hline Female & 10 & 67 & 7 & 100 & 17 & 77 \\
\hline Male & 5 & 33 & 0 & 0 & 5 & \\
\hline Total & 15 & 100 & 7 & 100 & 22 & 100 \\
\hline
\end{tabular}


Table 6 show the profile of respondents as to civil gender, it can be gleaned from this table that 10 or 67 percent of experts are female, 5 or 33 percent are male. On the other hand, all the 7 or 100 percent of math teachers are female.

The research instruments used are set of questionnaires as the method of gathering data and survey questionnaire. For the data gathering procedure:

1. Asking permission from the school president.

2. Constructed and developed the research instruments to be used in the study for validation.

3. Distributed the instruments to the experts and teachers in Mathematics as respondents.

4. Administered the pretest to the group of the student respondents.

5. Gathered the scores in the pretest of the students' respondents.

6. Conducted survey to Mathematics teachers and experts to assess the acceptability of the teaching material, based on the following criteria: introduction, objectives, content, application, evaluation, clarity, presentation, and usefulness.

7. Lessons on chapters 1-3 of the second quarter were presented to the students' respondents using the worktext.

8. Gathered the scores in the posttest of respondents.

9. Collected the data for treatment with due consideration of sub-problems and hypothesis. For the statistical treatment of the data they used: percentage, mean percentage score, weighted mean, and the t-test of significant difference between two means of dependent variable.

\section{Results}

The following are the finding of the specific problems raised in the study:

For the last 3 years which is from 2014 - 2017, 2014-2015 the mean grade or performance of the students is 26.7 which has the interpretation as low, 25.87 for the year 2015-2016 which also has the interpretation as low, also for the year 2016-2017 which has the mean of 76.37. The overall interpretation was low which brought the researcher to make a teaching material which would make the academic performance of the students better.

1. Based on the findings, the performance of the students for the last 3 years was low. From that, the researcher decided to make a worktext as a teaching material in teaching Mathematics specifically in Grade 7.

2. The supplementary teaching material was assessed by the experts and Math teachers on how acceptable it is in terms of: introduction, objectives, content, application, evaluation, clarity, presentation and usefulness. From the table shown for each variable, it shows that the proposed supplementary teaching material is acceptable.

3. Based on the findings, there is no significant difference between the evaluations of the two groups of respondents on the supplementary teaching material level of acceptability.

4. Based on the findings, there is a significant difference between the pretest and posttest of the students after using the proposed teaching material. It was shown that the teaching material was advantageous to the students' performance because after using the teaching material their performance became better.

\section{Discussion}

1. What is the academic performance of the students in Grade 7 mathematics for the last 3 years?

In the school year 2014-2015, 2015-2016, and 2016-2017 academic performance of mathematics for Grade 7 students were all interpreted as low academic performance.

2. Based on the finding, what Supplementary Teaching Material may be developed?

Measurements, algebraic expressions, and linear equations and inequalities in one variable.

3. How acceptable is the Supplementary Teaching Material as assessed by teachers and experts in terms of:

Introduction: All variables were assessed as highly acceptable ranking variable 1 as first in terms of introduction. Variable 3, 5, 2 and 3 were also assessed as highly acceptable ranking them from 2-5 respectively. Objectives: Variable 3 and 5 were both assessed as highly acceptable and ranked first in terms of objectives. Variable 1,2 and 4 were also assessed as highly acceptable ranking them from 3-5 respectively. Content: Variable 4 was assessed as highly acceptable ranking it first in terms of content. Variable 2, 3, 1 , and variable 5 were also assessed as highly acceptable ranking them from 2-5 respectively. Application: Variable 1 was assessed as highly acceptable ranking it first in terms of application. Variable 5, 4, 3 and 2 were all also assessed as highly acceptable ranking them from 2-5 respectively. Evaluation: Variable 1 is assessed as highly acceptable ranking it first in terms of evaluation. Variable 2, 3, 4 and 5 were all also assessed as highly acceptable ranking them from 2-5 respectively. Clarity: Variable 4 is assessed as highly acceptable ranking it first in terms of clarity. Variable 3, 1,2 and 5 were all also assessed as highly acceptable ranking them from 2-5 respectively. Presentation: Variable 3 was assessed as highly acceptable ranking it first in terms of presentation. Variable 1, 5, 4, and 2 were also all assessed as highly acceptable ranking them from 2-5 respectively. Usefulness: Variable 1 was assessed as highly acceptable ranking it first in terms of usefulness. Variable 5, 3, 2 , and 4 were all also assessed as highly acceptable ranking them from $2-5$ respectively.

4. Is there a significant difference in the assessment of the two groups of respondents on the aforementioned variables?

There is no significant difference between the evaluations of the two groups of respondents on the supplementary teaching material level of acceptability.

5. How do the students perform in the pretest and posttest before and after using the proposed Supplementary Teaching Material? Is there significant difference, if any? 
The study showed that the use of supplementary teaching material is advantageous that the performance of students become better after using the supplementary teaching material.

The null hypothesis is rejected which means that there is a significant difference between the pretest and posttest mean score of grade 7 students after using the supplementary teaching material.

Conclusion

Based on the finding of the study, the following conclusions were derived:

1. The performance of the students for the last 3 years was low.

2. The teacher should do something for the students to make their performance better. This is the reason why the researcher decided to make a worktext as a supplementary teaching material which could help the students and the teacher as well.

3. As a whole, the proposed supplementary teaching material in teaching grade 7 Mathematics was found by the two groups of respondents acceptable.

4. The two groups of respondents show that their evaluation about the proposed supplementary teaching material are both the same which is to accept the said teaching material.

5. After using the proposed teaching material the performance of the students improved.

As regards with the findings and conclusions, the following suggestions are recommended:

1. The students of Grade 7 Mathematics have to be given more supplementary teaching materials for a better performance.

2. The proposed teaching material should be tried out for the bigger classes of students for further validation.

3. Teacher should exert more efforts in teaching Mathematics and create motivational lessons and encouragement to strengthen the interest of the students to learn mathematics.

4. Teachers who are exerting more efforts in preparing their lessons should be given incentives or should be awarded.

5. The proposed teaching material needs further evaluation and assessment for the effectiveness to the students.

6. The result of this study be published and disseminated to all concerned to elicit feedback for the improvement of the study.

\section{Acknowledgements}

Every challenging work needs self-efforts as well Guidance of elders especially those who were very close to our heart. My humble effort I dedicate to my sweet and loving Father \& Mother Whose affection, love, encouragement and prays of days And night make me able to get such success and honor, along with all hard working and respected teachers.

\section{References}

[1] Balando, D. S, Developmental of Interactive Instructional Materials on Selected Topics in Business Mathematics. (Unpublished Thesis), EARIST, Manila, 2008.

[2] Kirk, L. M, Technology's Edge: The Educational Benefits of Computer-Aided Instruction, AmericanEconomic Journal: Economic Policy. Retrieved.www.icanlearn.com/results/. 2011.

[3] Magcalen, M. E. A, Computer-Aided Instructional Materials in Solid Mensuration: An Intervention to Problem Solving Skills of Engineering Students. (Unpublished Thesis), EARIST, Manila, 2011

[4] Acuna, B.M, Interacting Multimedia Instructional Materials; a Guidance Intervention Model in Teaching Mathematics for Grade 11. (Master's Thesis), Eulogio “Amang” Rodriguez Institute of Science and Technology, Manila, 2010.

[5] Nicdao, E. C, Development and Evaluation of Interactive Instructional Materials in Geometry in Elementary Grades. (Master Thesis), Manila: Philippine Normal University, 2013.

[6] Tenedero, N. S,Understanding vs. memorizing: Breakthrough education, Manila Bulletin, Philippines,Nov.2010.

[7] Clark, R. C, Developing Technical Training: A structured approach for developing classroom and Computer based instructional materials, San Francisco, 2008.

[8] Aguinaldo, R. M, Evaluation of an Activity Based Material Instructional on Selected Topics in Trigonometry (Master Thesis)., Manila: Philippine Normal University, 2012.

[9] Floirendo, M. M, Mathematics Society of the Philippines Convention, Davao City, May 27-28, 2009.

[10] Zulueta, F. M, Principles and Methods of Teaching, National Bookstore, Manila, Philippines, 2006.

\section{Biography}

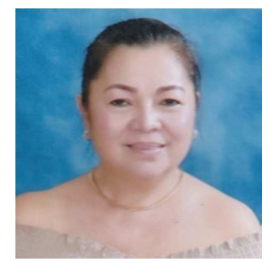

Meriam Villareal Dela Cruz graduated with the degree of Bachelor of Science major in Mathematics at FEATI University Sta.Cruz, Manila Philippines. She earned her master's degree, Master of Arts in Teaching major in Mathematics Education and her doctorate degree, Doctor of Education (Ed.D) major in Educational Management at Eulogio "Amang” Rodriquez Institute of Science and Technology (EARIST) Manila, Philippines and published different researches both locally and internationally since 2008 up to present. Presently, she is a graduate program professor at Eulogio "Amang" Rodriquez Institute of Science and Technology (EARIST) Manila, Philippines and Greenville College, Pasig City Philippines. 